NASA/TM-2009-215666

\title{
Attenuation of FJ44 Turbofan Engine Noise With a Foam-Metal Liner Installed Over-the-Rotor
}

Daniel L. Sutliff and Dave M. Elliott

Glenn Research Center, Cleveland, Ohio

Michael G. Jones

Langley Research Center, Hampton, Virginia

Thomas C. Hartley

Williams International, Walled Lake, Michigan 


\section{NASA STI Program . . . in Profile}

Since its founding, NASA has been dedicated to the advancement of aeronautics and space science. The NASA Scientific and Technical Information (STI) program plays a key part in helping NASA maintain this important role.

The NASA STI Program operates under the auspices of the Agency Chief Information Officer. It collects, organizes, provides for archiving, and disseminates NASA's STI. The NASA STI program provides access to the NASA Aeronautics and Space Database and its public interface, the NASA Technical Reports Server, thus providing one of the largest collections of aeronautical and space science STI in the world. Results are published in both non-NASA channels and by NASA in the NASA STI Report Series, which includes the following report types:

- TECHNICAL PUBLICATION. Reports of completed research or a major significant phase of research that present the results of NASA programs and include extensive data or theoretical analysis. Includes compilations of significant scientific and technical data and information deemed to be of continuing reference value. NASA counterpart of peer-reviewed formal professional papers but has less stringent limitations on manuscript length and extent of graphic presentations.

- TECHNICAL MEMORANDUM. Scientific and technical findings that are preliminary or of specialized interest, e.g., quick release reports, working papers, and bibliographies that contain minimal annotation. Does not contain extensive analysis.

- CONTRACTOR REPORT. Scientific and technical findings by NASA-sponsored contractors and grantees.
- CONFERENCE PUBLICATION. Collected papers from scientific and technical conferences, symposia, seminars, or other meetings sponsored or cosponsored by NASA.

- SPECIAL PUBLICATION. Scientific, technical, or historical information from NASA programs, projects, and missions, often concerned with subjects having substantial public interest.

- TECHNICAL TRANSLATION. Englishlanguage translations of foreign scientific and technical material pertinent to NASA's mission.

Specialized services also include creating custom thesauri, building customized databases, organizing and publishing research results.

For more information about the NASA STI program, see the following:

- Access the NASA STI program home page at http://www.sti.nasa.gov

- E-mail your question via the Internet to help@ sti.nasa.gov

- Fax your question to the NASA STI Help Desk at $443-757-5803$

- Telephone the NASA STI Help Desk at 443-757-5802

- Write to: NASA Center for AeroSpace Information (CASI) 7115 Standard Drive Hanover, MD 21076-1320 
NASA/TM-2009-215666

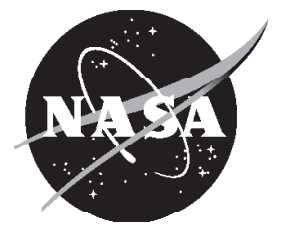

\title{
Attenuation of FJ44 Turbofan Engine Noise With a Foam-Metal Liner Installed Over-the-Rotor
}

\author{
Daniel L. Sutliff and Dave M. Elliott
}

Glenn Research Center, Cleveland, Ohio

Michael G. Jones

Langley Research Center, Hampton, Virginia

Thomas C. Hartley

Williams International, Walled Lake, Michigan

Prepared for the

30th Aeroacoustics Conference

sponsored by the American Institute of Aeronautics and Astronautics

Miami, Florida, May 11-13, 2009

National Aeronautics and

Space Administration

Glenn Research Center

Cleveland, Ohio 44135 


\section{Acknowledgments}

The authors would like to acknowledge the dedicated efforts of the support crew in the Aero-Acoustic Propulsion Laboratory (AAPL); especially Mark Jacko, Lenny Smith, Ed Mysliwiec, Bruce Groene, Gary Novotnak, Vic DeCapite, and Bill Magas. Dr. Cheryl Bowman of the Glenn Research Center's Advanced Metallics Branch provided critical fabrication and operational assistance. Dr. Mohan Hebsur, formerly of Ohio Aerospace Institute, provided the foundational work on foam metal liners. The Williams International team members Dean Musgrave, Jim Dorer, Dennis Sochocki, Dan Schester, Chris Nona, Glenn Guenther, Ryan Ellis, Big Doug Meenderink, Brian McCaffrey, Bernie Bobola, Bill Rayburn, Sean Harding, and Dave Prescott put forth their best ideas, time, and efforts and proved once again that it takes a total team effort to achieve success.

Trade names and trademarks are used in this report for identification only. Their usage does not constitute an official endorsement, either expressed or implied, by the National Aeronautics and Space Administration.

Level of Review: This material has been technically reviewed by technical management.

Available from

NASA Center for Aerospace Information 7115 Standard Drive

Hanover, MD 21076-1320
National Technical Information Service 5285 Port Royal Road Springfield, VA 22161

Available electronically at http://gltrs.grc.nasa.gov 


\title{
Attenuation of FJ44 Turbofan Engine Noise With a Foam-Metal Liner Installed Over-the-Rotor
}

\author{
Daniel L. Sutliff and Dave M. Elliott \\ National Aeronautics and Space Administration \\ Glenn Research Center \\ Cleveland, Ohio 44135 \\ Michael G. Jones \\ National Aeronautics and Space Administration \\ Langley Research Center \\ Hampton, Virginia 23681 \\ Thomas C. Hartley \\ Williams International \\ Walled Lake, Michigan 48390
}

\begin{abstract}
A Williams International FJ44-3A 3000-lb thrust class turbofan engine was used as a demonstrator for a FoamMetal Liner (FML) installed in close proximity to the fan. Two FML designs were tested and compared to the hardwall baseline. Traditional single degree-of-freedom liner designs were also evaluated to provide a comparison. Farfield acoustic levels and limited engine performance results are presented in this paper. The results show that the FML achieved up to $5 \mathrm{~dB}$ Acoustic Power Level (PWL) overall attenuation in the forward quadrant, equivalent to the traditional liner design. An earlier report presented the test set-up and conditions.
\end{abstract}

\section{Nomenclature}

$\begin{array}{llll}\text { FML } & \text { Foam-Metal Liner } & \zeta & \text { acoustic impedance } \\ \text { OTR } & \text { Over-the-Rotor } & \varsigma_{c} & \text { characteristic impedance } \\ \text { HW1 } & \text { original hardwall flow path } & \Gamma & \text { propagation constant } \\ \text { HW2 } & \text { modified hardwall flow path } & d & \text { sample depth } \\ \text { A1 } & \text { Target FML design (80 ppi/in.; } & a & \text { parameter } \\ & \text { 8\% density) } & m & \text { mass flow } \\ \text { A1t } & \text { FML w/forward 1/2-section taped } & P_{s} & \text { static pressure } \\ \text { A2 } & \text { Target FML design (40 ppi/in.; } & P_{t} & \text { total pressure } \\ & \text { 8\% density) } & T_{t} & \text { total temperature } \\ \text { SDOF1 } & \text { Single degree-of-freedom liner } & r_{o}, r_{i} & \text { outer/inner radius } \\ & \text { (designed for BPF at100\% N1c) } & \gamma & \text { specific heat ratio } \\ \text { SDOF2 } & \text { Single degree-of-freedom liner (designed } & \gamma & \text { gas constant } \\ & \text { for BPF at 75\% N1c) } & R & \text { directivity angle } \\ \text { PWL } & \text { Acoustic Power Level } & \Theta & \\ \text { N1c } & \text { Corrected Fan Speed } & & \end{array}$

\section{Introduction}

Significant reduction in aircraft noise is required to meet ongoing noise regulation in the USA and Europe. Since the turbofan engine is a large contributor to aircraft noise, any overall reduction in aircraft noise must include engine noise reduction (Ref. 1). The NASA focus area-Fundamental Aeronautics, Subsonic: Fixed Wing 
Program - emphasizes developing technologies for reducing noise for subsonic aircraft. This specific program described herein was initiated under the Innovative Partnerships Program that enables cost-shared projects to address barriers and remove obstacles to technology development. These efforts could lead to larger development partnerships and projects that would be of greater significance and value to NASA.

Acoustic liners in current aircraft engines are generally located in the inlet and/or the aft fan duct. If the liner is placed nearer to the fan rotor, or over the rotor, preliminary tests (Ref. 2) suggested that significant additional noise attenuation could be realized. From these tests, was deduced that liners placed in this region provide a pressure release surface, mitigating the acoustic near field and thereby reducing the farfield noise emitted by the engine. Typically, acoustic liners have not been implemented over the rotor due to aerodynamic and structural considerations as well as the inability of liners to withstand rotor tip rubs. However, if a liner were made of metallic foam with the suitable acoustic properties, these issues could be addressed.

A prototype Foam-Metal Liner (FML) was successfully developed and tested on a NASA Glenn Research Center low-speed, concept test fan. This test demonstrated the potential of FML for reducing rotor noise. Bench top lab tests indicated that the metal foam liner could withstand expected engine environments. Undetermined was the acoustic performance of FML in a high-speed, high-pressure ratio engine environment and the impact of the foammetal liner on the aerodynamic performance of the engine.

A Williams International FJ44-3A engine was tested in the Aero-Acoustic Propulsion Laboratory (AAPL) (Ref. 3) located at the NASA Glenn Research Center. The FJ44 is a very high tip speed fan. Several liner configurations were tested in addition to the hardwall baseline. Two FML were fabricated and tested. The predicted optimum design was an 80 pores/in. (ppi), $8 \%$ dense open cell foam metal liner. This liner was also tested in a partially taped configuration to localize the attenuation mechanism. An off-design liner ( $40 \mathrm{ppi}, 8 \%$ dense) was tested to evaluate trend lines. In order to compare noise reduction benefits to the state-of-the-art, two single degree-of-freedom liners were designed using current design methodologies (Ref. 4) and tested on the FJ44.

\section{Liner Design and Installation}

\section{Impedance Tube Testing}

The liner characteristics were quantified in the NASA Langley Research Center Normal Incidence Tube rig. The experimental evaluation was conducted in three steps (Ref. 5). First, the Two-Microphone Method (Refs. 6 and 7) was used to measure the normal incidence acoustic impedance of two samples, comprised of two and four 0.425 -in. thick layers (the only thicknesses available) of foam-metal, respectively. Next, the Two-Thickness Method (Ref. 8) was used to educe intrinsic acoustic properties from these component measurements. Finally, the TwoMicrophone Method was used again to measure the normal incidence acoustic impedance of a third sample, comprised of three 0.425 -in. thick layers of foam, and the measured impedance spectra was compared with the corresponding impedance spectra predicted from these intrinsic acoustic properties. Figure 1 shows a sketch of the NASA Langley normal incidence tube with supporting instrumentation.

\section{Two-Microphone Method}

The Two-Microphone Method was used with the NASA Langley normal incidence tube (Fig. 3) to determine the surface impedance of each sample. These data were generated with a random noise acoustic source, at overall sound pressure levels (OASPL, integrated over frequency range of 500 to $3000 \mathrm{~Hz}$ ) of 120 and $140 \mathrm{~dB}$, as measured

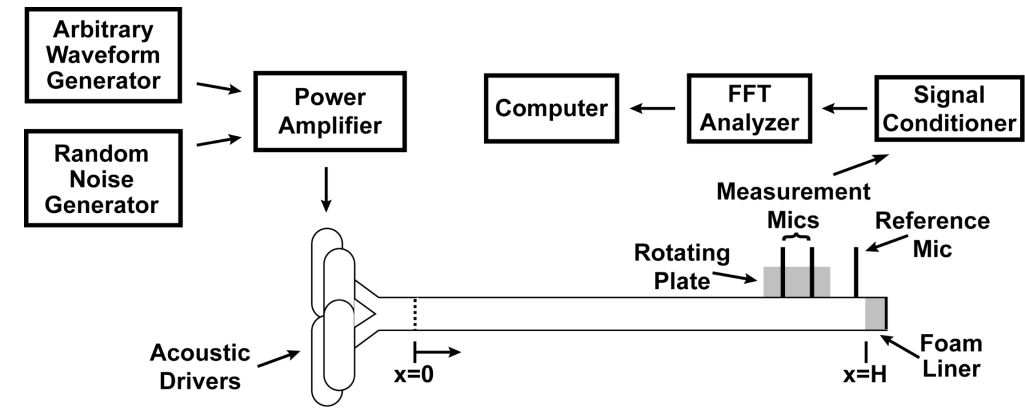

Figure 1.-Sketch of NASA Langley Normal Incidence Tube. 
by the reference microphone flush-mounted 0.25 -in. from the surface of the sample. Data were acquired at frequencies from 500 to $3000 \mathrm{~Hz}$, in increments of $25 \mathrm{~Hz}$. In total, eight tests were conducted for this investigation (two source levels, four samples). As expected, results acquired with each sample were observed to be independent of the source OASPL. As expected, results acquired with each sample were observed to be independent of the source OASPL over the range of OASPLs used in this study. This was also observed to be true for the foams considered in this study. Thus, for the sake of brevity, only the results for an OASPL of $140 \mathrm{~dB}$ are presented in this report.

\section{Two-Thickness Method}

The Two-Thickness Method is well established for educing the intrinsic properties (characteristic impedance, $\zeta_{c}$, and propagation constant, $\Gamma$ ) of bulk absorbing structures. The core of this method is the solution of the following two equations:

$$
\begin{aligned}
& \zeta_{1}=\zeta_{c} \operatorname{coth}\left(\Gamma d_{1}\right) \\
& \zeta_{2}=\zeta_{c} \operatorname{coth}\left(\Gamma d_{2}\right)
\end{aligned}
$$

where $\zeta_{1}$ and $\zeta_{2}$ represent two measured surface impedances on two separate test samples of depths $d_{1}$ and $d_{2}$, taken from what is assumed to be a homogeneous, continuous structure. In the current study, the analysis is greatly simplified by selecting sample depths such that $d_{2}=2 d_{1}$. Specifically, surface impedance spectra, $\zeta_{1}$ and $\zeta_{2}$, measured with 0.85 - and 1.70-in. thick samples (two and four layers of foam-metal), respectively, were used as input for the two-thickness method. Based on these measured impedance spectra, the characteristic impedance and propagation constant spectra of this type of foam-metal can be determined as follows:

$$
\begin{gathered}
\zeta_{c}=\sqrt{\zeta_{1}\left(2 \zeta_{2}-\zeta_{1}\right)} \\
\Gamma=\Gamma_{r}+I \Gamma_{i}=\frac{1}{2 d_{1}} \log \left(\frac{1+a}{1-a}\right) \\
a=\sqrt{\frac{2 \zeta_{2}-\zeta_{1}}{\zeta_{1}}}
\end{gathered}
$$

From these two complex quantities, the attenuation and phase rates can be determined. The attenuation rate $\left(\Gamma_{r}\right)$ is the rate at which the amplitude of the acoustic wave decays as it travels through the sample. Correspondingly, the phase rate $\left(\Gamma_{i}\right)$ is the rate at which the phase of the acoustic wave varies as it travels through the sample. If the parent material of the two initial samples is sufficiently uniform, such that the intrinsic properties of the material can be successfully educed from these two samples, the impedance $\zeta_{s}$ of a third sample with thickness $d_{s}(1.275$-in. for this study) can then be determined using:

$$
\zeta_{s}=\zeta_{c} \operatorname{coth}\left(\Gamma d_{s}\right)
$$

A comparison between the measured impedance of the third sample and the impedance predicted using the $\zeta_{c}$ and $\Gamma$ educed using the two-thickness method can be used to assess the "validity" of the educed parameters. The $L^{2}$-Norm, $L^{2}$, is used for this evaluation. It is computed as follows:

$$
L^{2}=\frac{1}{N} \sqrt{\sum_{i=1}^{N}\left|\zeta_{m, i}-\zeta_{p, i}\right|^{2}}
$$

where $\zeta_{m, i}$ and $\zeta_{p, i}$ are the measured and predicted impedances, respectively, at the $i$ th frequency, and $N$ is the total number of frequencies used in the evaluation. Ideally, the value of $L^{2}$ should be zero, indicating exact comparison between the measured and predicted impedances for samples with depths that are different from those used as input to the method. Thus, any departure from zero is (1) a measure of experimental error, and/or (2) a breakdown of the continuum assumption (e.g., material imperfections). 


\section{Results}

The measured impedance spectra for 0.85- and 1.70-in. thick samples (two and four layers of foam-metal) are provided in Figure 2. As described earlier, these impedance spectra were used as input to the two-thickness method. Equations (3) to (5) were then used to compute the corresponding characteristic impedance and propagation constant for this foam-metal. These intrinsic acoustic properties were used to predict the acoustic impedance spectrum for the 1.275-in. thick sample. A comparison of the predicted and measured acoustic impedance spectra is provided in Figure 3. The comparison is exceptional, indicating the intrinsic properties of the foam-metal have been successfully educed. The $L^{2}$-Norm, $L^{2}$, computed from a comparison of the predicted and measured acoustic impedance spectra for this sample has a value of 0.002 . For the frequencies used in this study ( $25 \mathrm{~Hz}$ increments from $400 \mathrm{Ho} 3000 \mathrm{~Hz}$ ), this corresponds to an average error between the measured and predicted resistances and reactances (real and imaginary components of acoustic impedance) of $0.015 \rho c$ ( $\rho c$ is the characteristic impedance of air). This extremely small error provides confidence in the ability of the model to predict the normal incidence acoustic impedance spectra that would be measured for any sample thickness within reasonable proximity to those included in the current study.

These impedances were then used to predict the absorption coefficient spectra for 1- and 2-in. thick samples of this foam type (Fig. 4). Based on these results, the 80 ppi/in., $8 \%$ density metal alloy was selected as the optimal configuration for further detailed evaluation. A similar process was conducted for a second configuration of foammetal, consisting of a $40 \mathrm{ppi} / \mathrm{in}$., $8 \%$ density metal alloy. This process indicated this lower ppi configuration was suitable for comparison with the optimal foam-metal configuration.

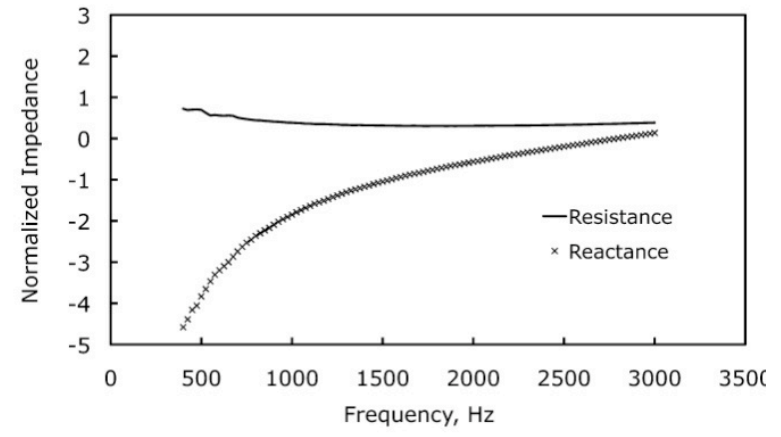

(a) 0.85 -in. thick

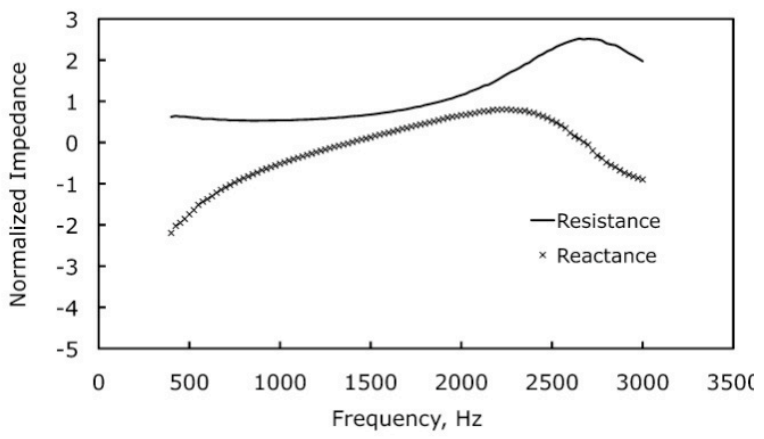

(b) 1.70 -in. thick

Figure 2.-Normal Incidence Acoustic Impedance Foam-Metal Samples.

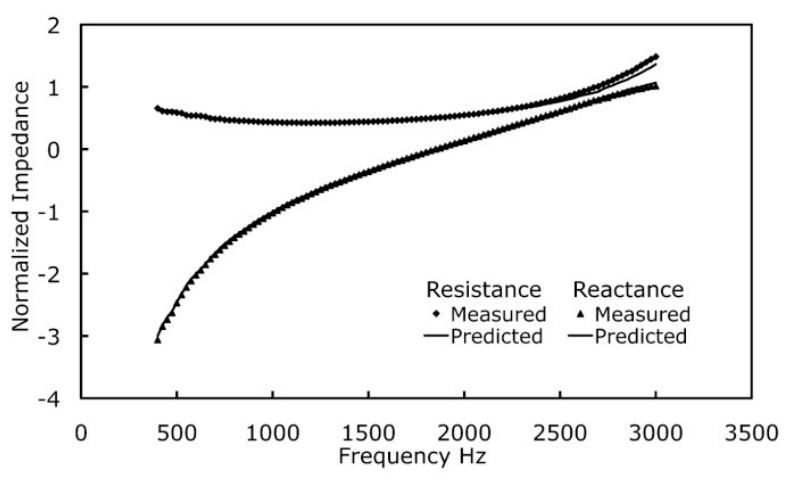

Figure 3.-Predicted and Measured Acoustic Impedance Spectra for 1.275-in. Thick Sample.

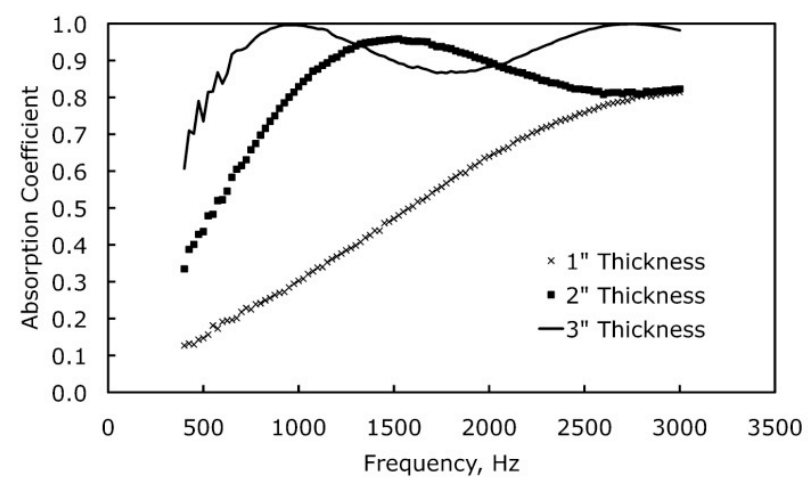

Figure 4.-Absorption Coefficient Spectra for Three Thickness of $80 \mathrm{ppi}, 8 \%$ Density Foam-Metal. 


\section{Liner Installation and Engine}

The existing fan shroud of the FJ44-3A was modified to incorporate the foam metal material. Two "rings" of foam metal were installed into the fan shroud. The 1 st ring, $11 / 4 \mathrm{in}$. long, was entirely upstream of the fan, the 2 nd ring, $11 / 2$ in. long, spanned from just upstream of the fan to a little over $1 / 3$ of the fan blade projection. The duct outer wall was perforated to provide the appropriate cover sheet to allow an acoustic path into the liner material. The basic flow path was maintained with the exception that the circumferential ridges immediately over the fan path were reduced in depth to accommodate the foam metal. To account for this a 2 nd hardwall configuration was built with the same ridge depth, but was entirely hardwall (no perforate). Two FML shroud assemblies were manufactured an $80 \mathrm{ppi}$, and a $40 \mathrm{ppi}$, both having $8 \%$ density. Figure 5(a) shows the original flow path. Figure 5(b) shows a cross-section of the fan shroud with the FML in the "pockets". Figure 6 shows a closeup photograph of the fan blade tips over the perforated liner.

The Williams International FJ44-3A engine was tested in the AAPL (Ref. 9) located at the NASA Glenn Research Center. The AAPL dome is $65 \mathrm{ft}$ high and $130 \mathrm{ft}$ in diameter, providing an anechoic testing environment for engine component research and development. A photo of the engine mounted on the test stand is shown in Figure 7. Located nominally $50 \mathrm{ft}$ from a test model, an overhead fixed microphone array was used to acquire farfield acoustic data. A custom-built far-field microphone array was used to obtain sideline acoustic data at $10 \mathrm{ft}$. Inlet and bypass duct pressure and temperature rakes were used to obtain limited performance data. Details of the facility, and the installation and operation of the FJ44-3A for this test, are presented in Reference 3.

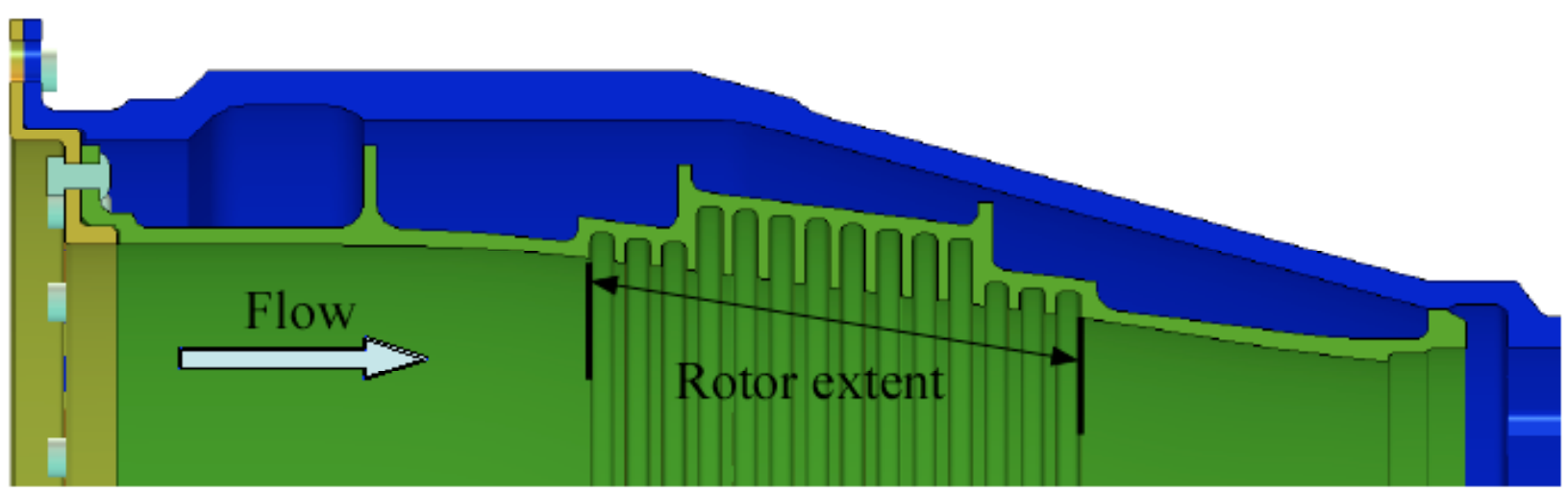

(a) Original Flow Path—Hardwall Configuration (HW1).

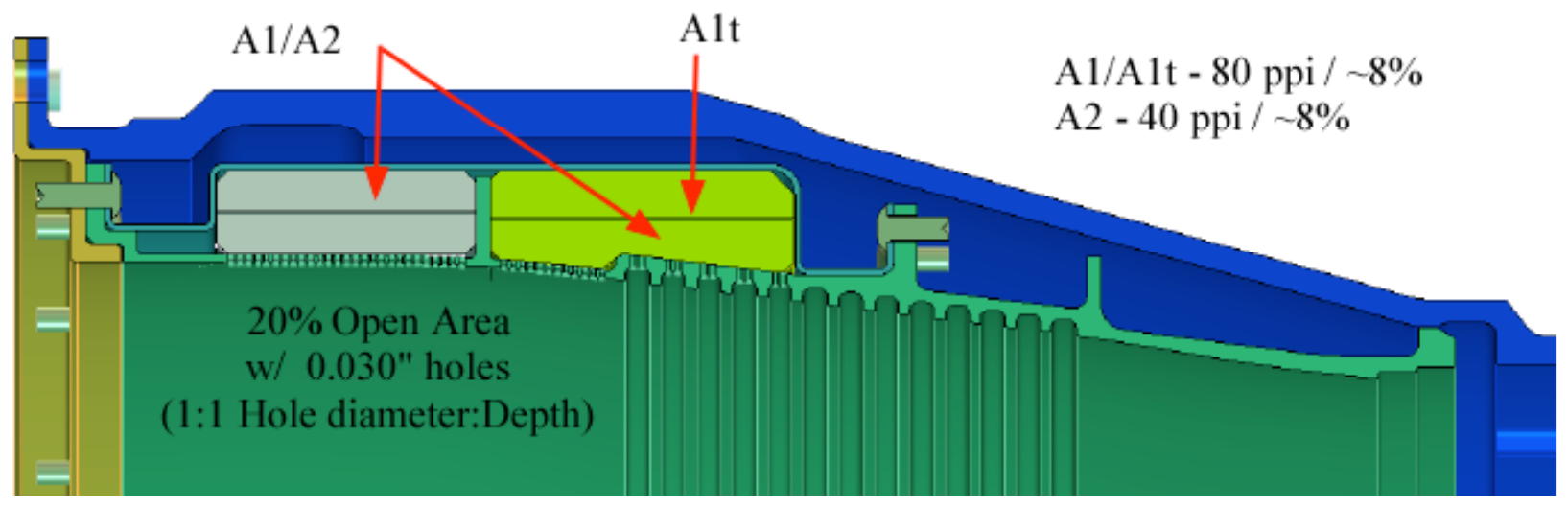

(b) FML Flow Path/New Matched Hardwall Configuration Without Perforate (HW2).

Figure 5.-Flow Path Schematics. 


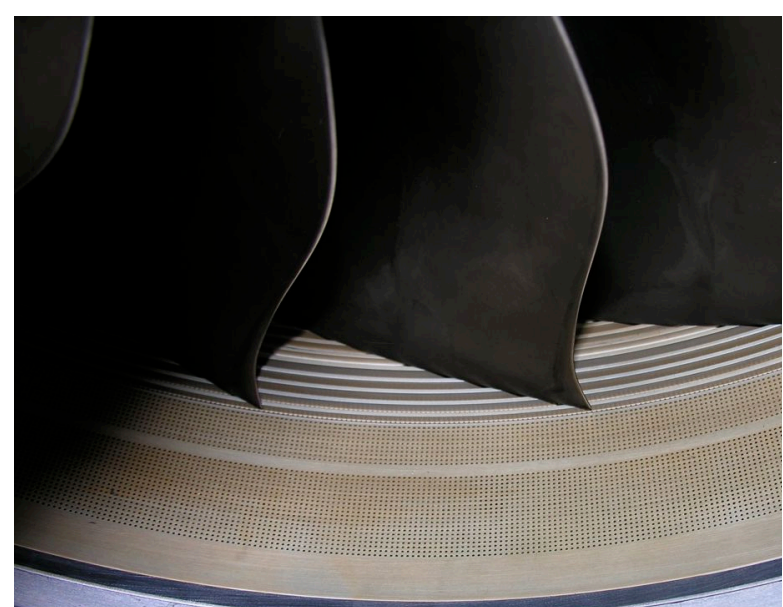

Figure 6.-Closeup of FML Installed OTR.

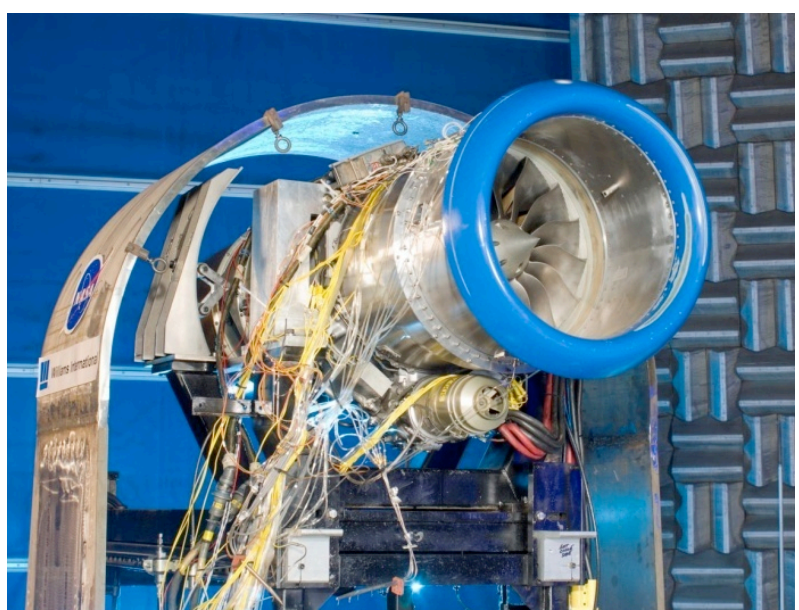

Figure 7.-FJ44 on Test Stand in AAPL.

\section{Farfield Acoustic Results}

\section{0-ft Arc Array Results}

Farfield acoustic directivities were acquired from 12 microphones placed at a 10 - $\mathrm{ft}$ radius from the duct centerline. These were in an arc equi-spaced from $0^{\circ}$ to $90^{\circ}$ as measured from the inlet axis. The spectra of each time history are processed in order to analyze the broadband content by removing the tones generated by the fan (shaft orders and harmonics) and integrating about a fan harmonic. This can be done exactly since the data are acquired synchronously to the shaft rotation. For example the $1 \mathrm{st}$ harmonic band is defined as the integration from 0.5 to 1.5 blades (B), the $2 \mathrm{nd}$ harmonic band from 1.5 to $2.5 \mathrm{~B}$, etc. (16 for the FJ44), so the 1 st harmonic band centered on 16 shaft orders and is the integration from 8 to 24 shaft orders (Fig. 8). The data can then be converted to power by squaring the pressure and multiplying by the appropriate area, then normalizing by specific acoustic impedance PWL. This reduction process can be done on the original time history or with the tones removed to obtain overall or broadband PWL. All acoustic data presented in this section are reduced using this process.

The overall, broadband, and tonal components of directivity in the 1st harmonic band that is generated from the design FML and hardwall baseline configurations are compared for two fan speeds in Figure 9. The lower speed, $70 \%$ N1c, has a fan tip speed less than Mach 1, but at 94\% N1c, it is well above Mach 1 . The lobed nature is seen in the tonal directivity below sonic tip speed and the FML attenuates this very well $\sim 15 \mathrm{~dB}$ reduction in the peak lobe. The tonal directivity in the higher-speed case is more uniform and the treatment is seen to be ineffective. The broadband component shows the "all modes" pattern for both fan speed cases. The broadband is attenuated $\sim 5 \mathrm{~dB}$ uniformly over the $90^{\circ}$ arc for the low speed case; a more modest 1 to $2 \mathrm{~dB}$ for the high-speed case. Since this fan is tone dominated similar observations are noted in the overall noise signature.

The integrated PWLs are shown in Figures 10 to 12 as a function of normalized N1c. The tonal (Fig. 10), broadband (Fig. 11), and overall (Fig. 12) components for the 1st (a) and 2nd (b) harmonic bands are presented. The left side plots provide power level spectra (absolute values not provided due to proprietary nature of data), and the right side plots provide delta between the power levels measured with the FML installed and those measured for a hardwall configuration.

The tone level plots at Blade Passing Frequency (BPF) show that the design FML (A1-80 ppi) yields significant reduction until the rotor tip speed is well above Mach 1 . There is considerable variation with speed. Taping the upstream section (A1t) of the liner reduces the attenuation by 2 to $4 \mathrm{~dB}$. The off-design liner, A2 (40 ppi) achieves slightly less attenuation and appears to be even less effective at sonic tip speeds. At 2 BPF, the target design liner is more effective and the attenuation is more consistent with speed. The liner A1 is $2 \mathrm{~dB}$ more effective than the liner A2. Both lose their effectiveness above Mach 1 tip speed, though the A1 configuration retains some effectiveness.

The broadband attenuation is significant for all configurations. The effectiveness of the treatment is likewise reduced above sonic tip speed, though still noticeable. It is less apparent which configuration is superior. At BPF the optimum configuration is dependent on fan speed, while at 2 BPF the attenuation achieved each configuration is similar below sonic rotor tip speed. At some fan speeds the shorter treatment, A1t, yields higher attenuation. This may be due to different perforate length generating effecting the interaction of the boundary layer noise with the fan.

The overall attenuation tends to look more like the tonal results since this fan is tone dominated in the inlet. 


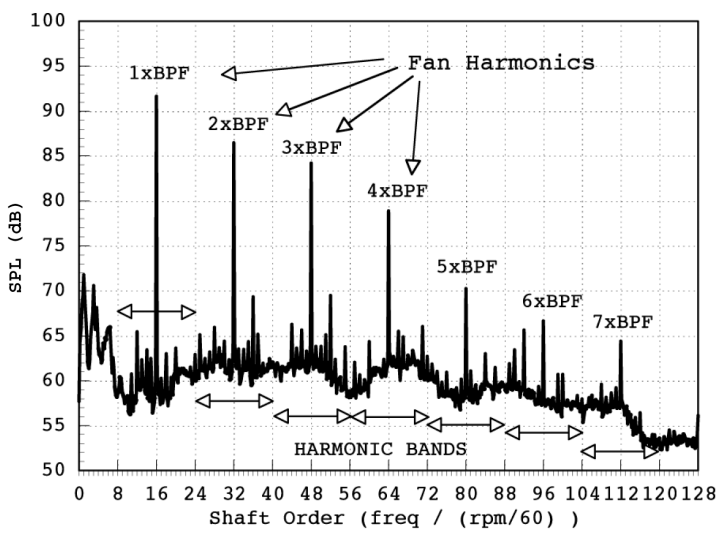

(a) Original Spectral Sample

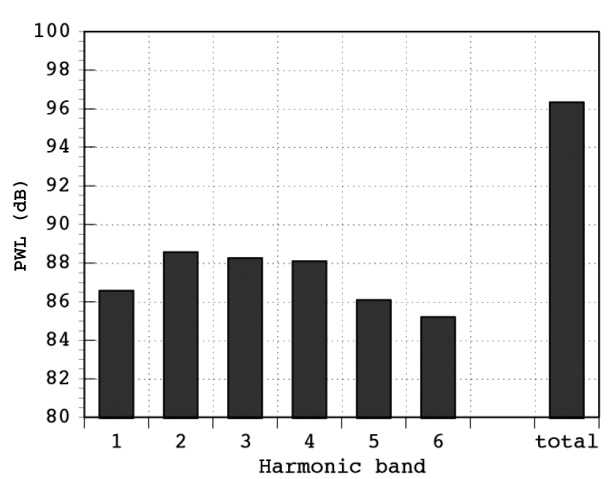

(c) Harmonic Bands

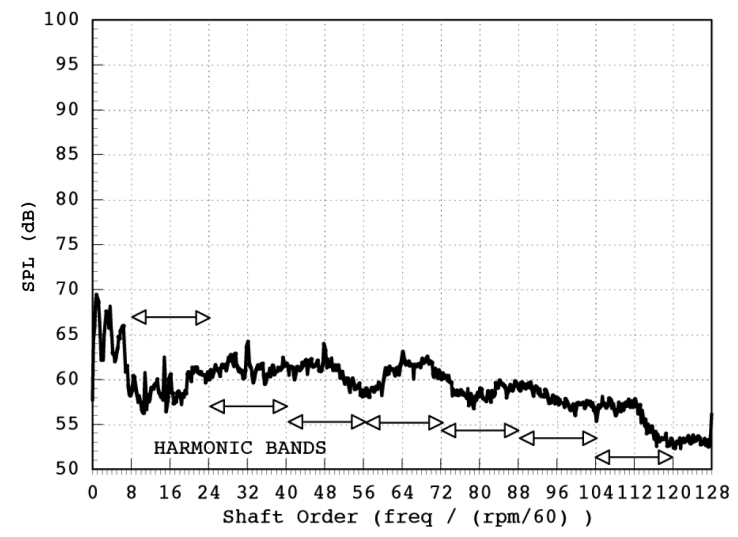

(b) Spectral Sample with Fan Harmonics Removed

1st harmonic band: integrate 8 to 24 shaft orders

2nd harmonic band: integrate 24 to 40 shaft orders

3rd harmonic band: integrate 40 to 56 shaft orders, etc.

Figure 8.-Illustration of Farfield Data Reduction into Harmonic Bands.

(5 dB / division)
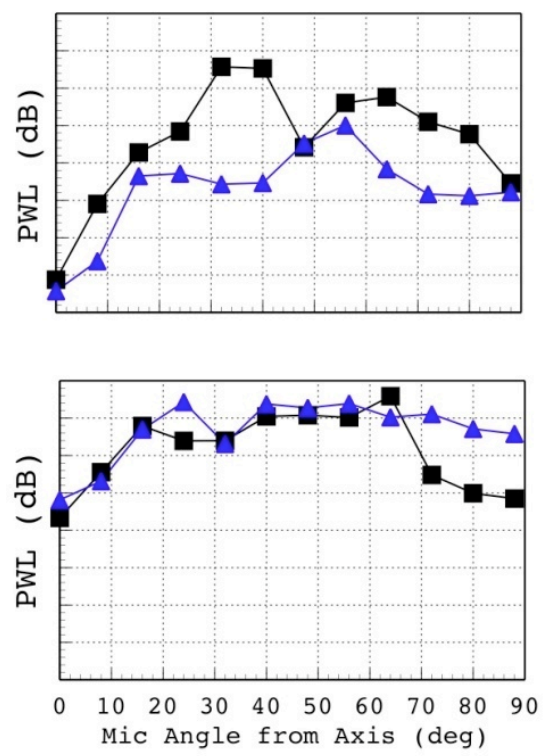

Tonal

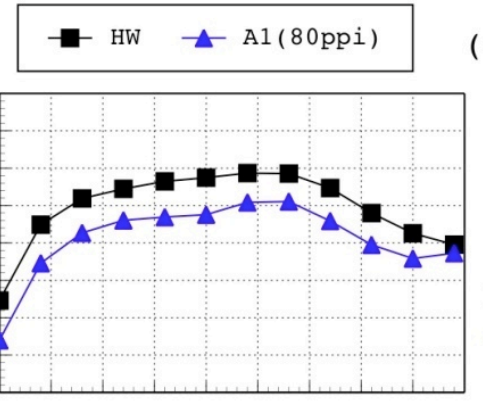

(identical scales on plots)
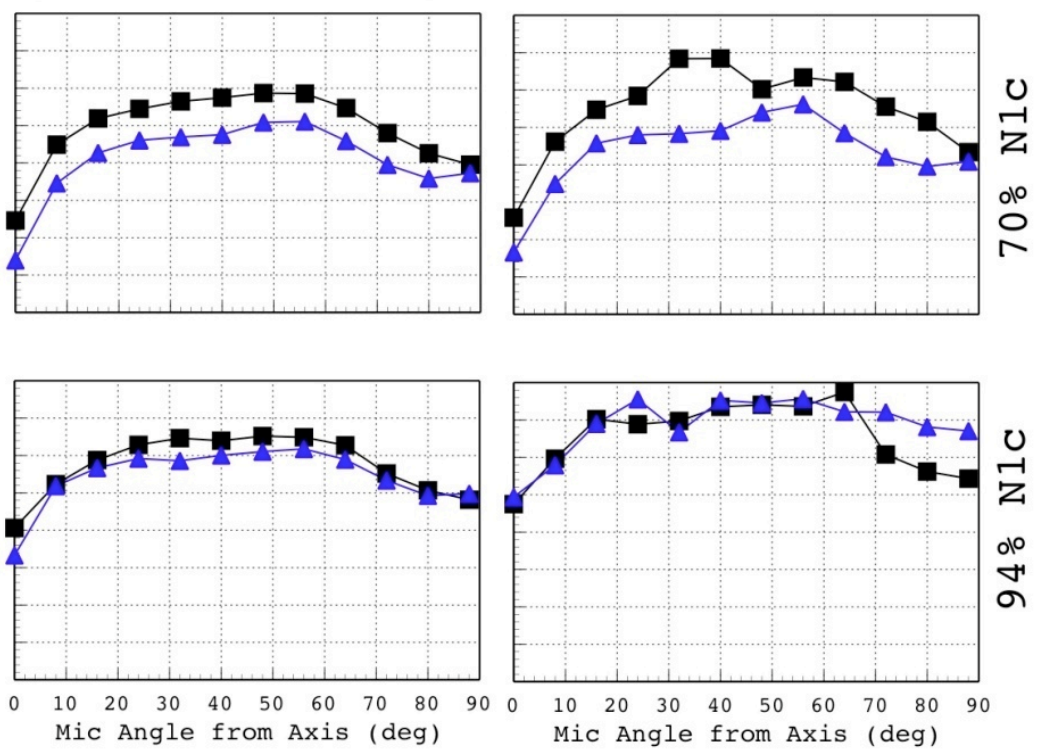

Broadband

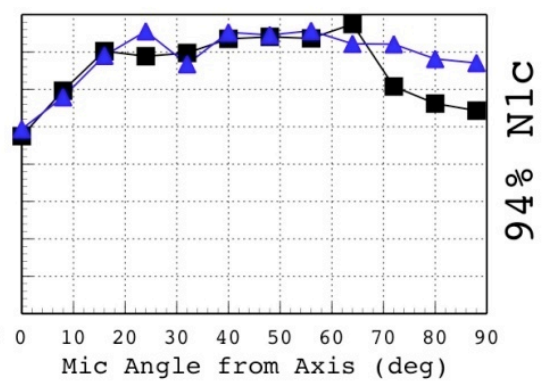

Overall

Figure 9.-1st Harmonic Band Directivity for Two Fan Speeds. 

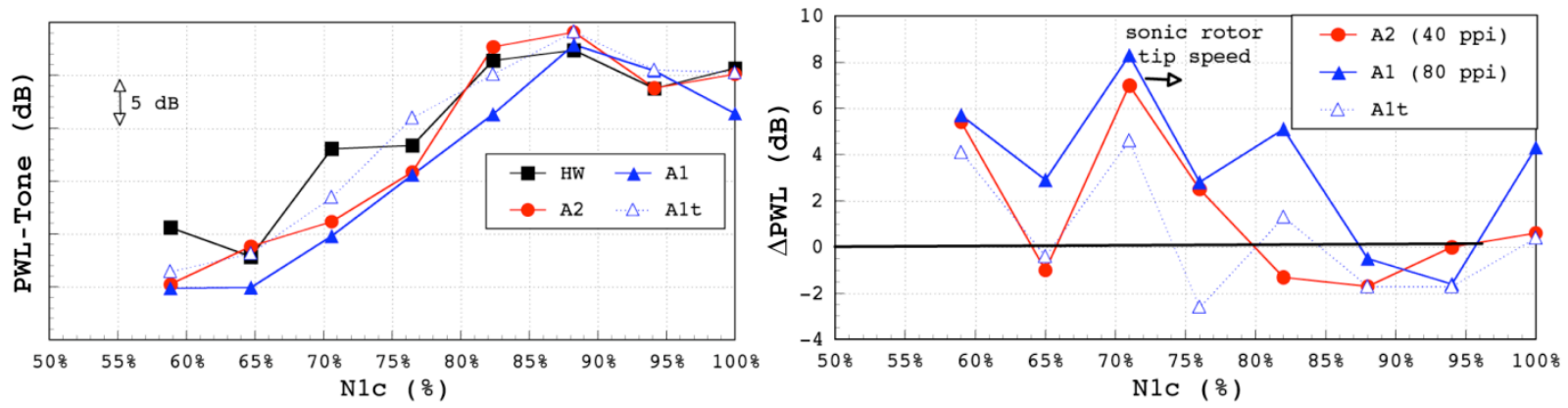

(a) $1 \mathrm{st} \mathrm{BPF}$
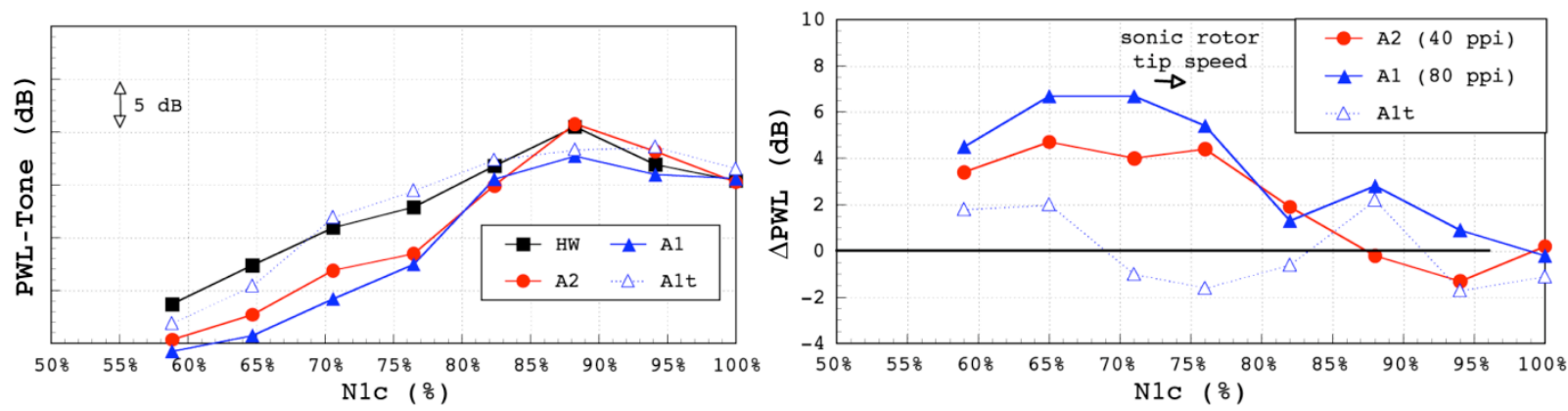

(b) 2nd BPF

Figure 10.-Tonal PWL for Several Configurations.
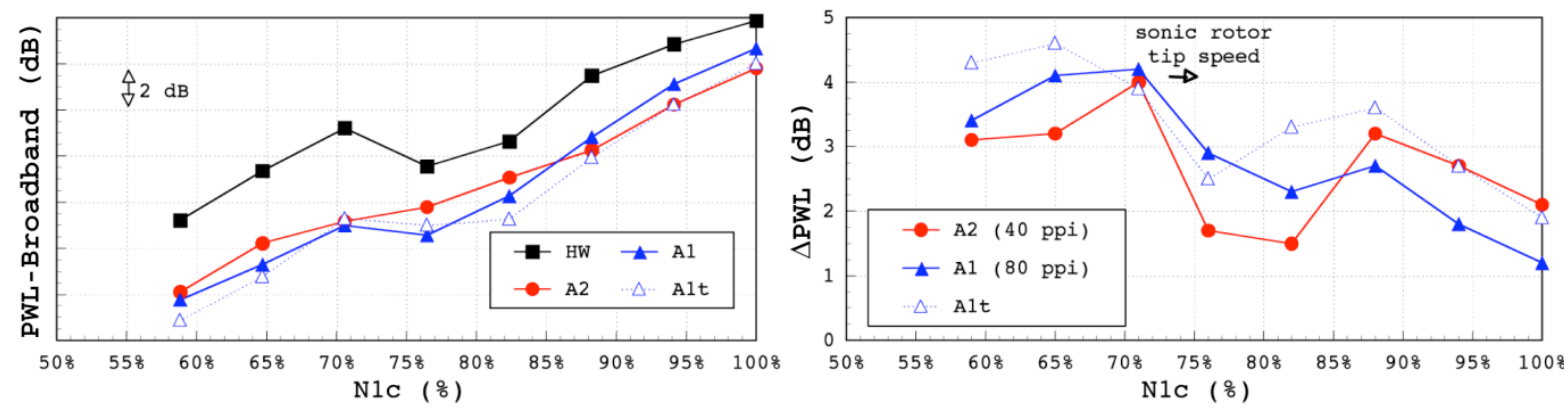

(a) 1st Harmonic Band
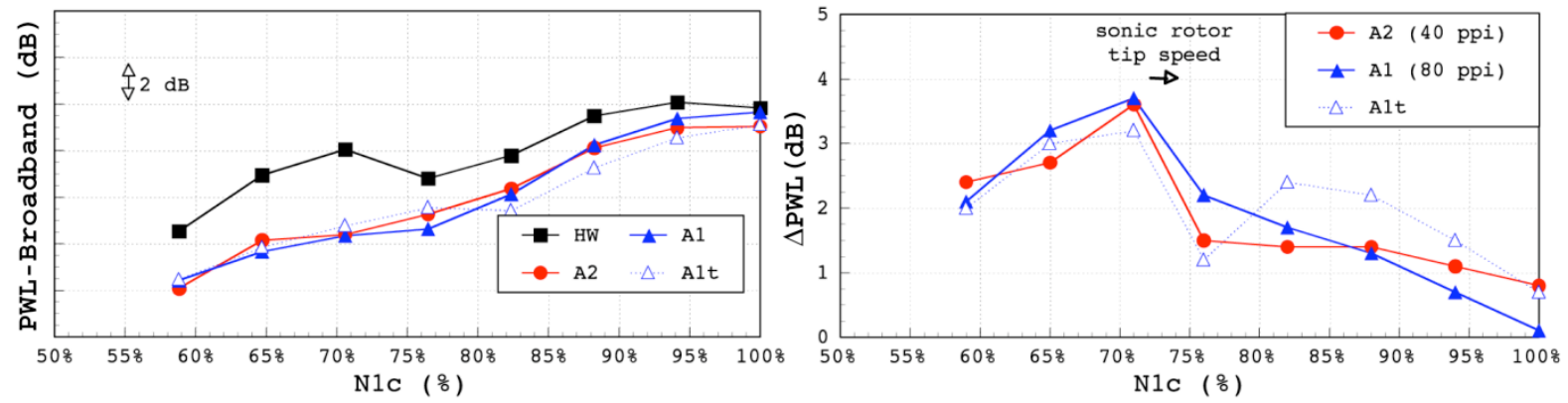

(b) 2nd Harmonic Band

Figure 11.-Broadband PWL for Several Configurations. 

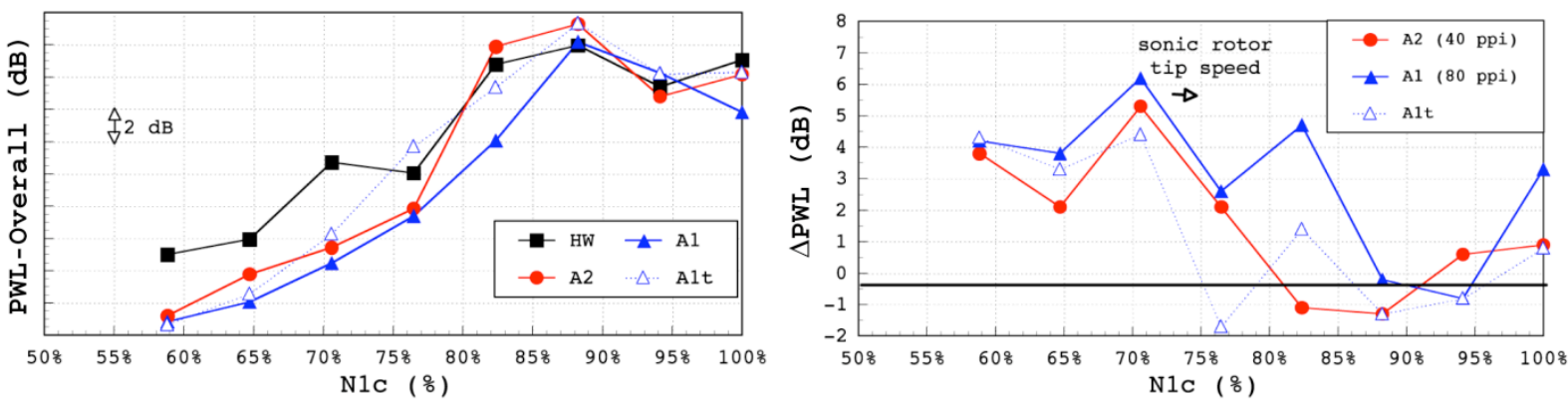

(a) 1st Harmonic Band
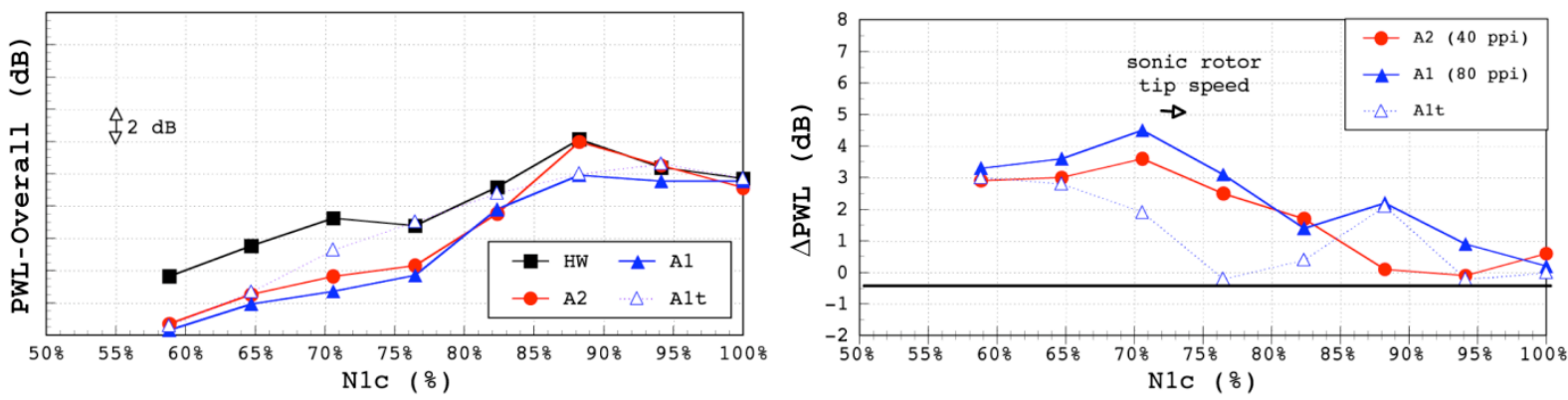

(b) 2nd Harmonic Band

Figure 12.-Overall PWL for Several Configurations.
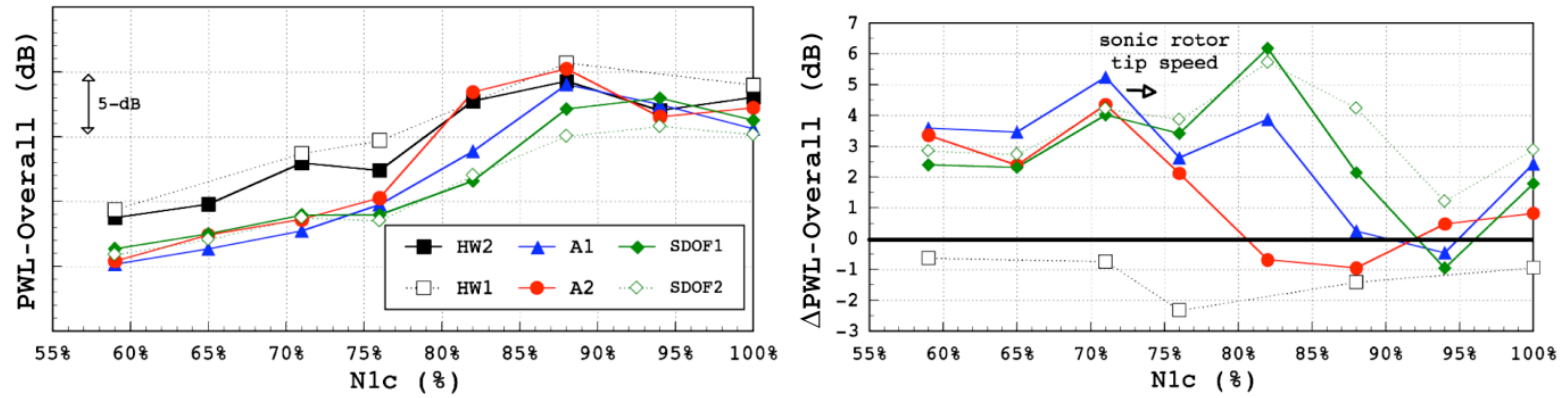

Figure 13.--Overall PWL for Several Configurations.

When evaluating novel noise-reduction concepts it is usually instructive to compare the attenuation achieved to that of the state-of-the-art. In this case, two single degree-of-freedom liners were designed and evaluated. Figure 13 provides this comparison. SDOF1 was a "thick" liner designed to attenuate the 1st BPF at 100\% N1c by coupling to the 2nd liner depth mode resonance. SDOF2 was a "thin" liner designed to attenuate the 1st BPF coupling to the 1st liner depth mode resonance (practical manufacturing limit resulted in a target $1 \mathrm{st}$ BPF at 74\% N1c). The SDOF liner location was in the traditional inlet position, well forward of the rotor plane and was 12-in. long. The attenuation levels are similar, though either SDOF liner better maintains its effectiveness above sonic tip speed. Since the Overthe-Rotor (OTR) FML achieves nearly the same attenuation with a much shorter length this indicates the apparent greater effectiveness could be due to rotor source modification. 


\section{Comparison to Overhead Array Results}

Farfield data were also acquired from an overhead array of 28 microphones, between $20^{\circ}$ and $140^{\circ}$ from the forward axis. The data from this array were processed in the traditional method (fixed sample rate). Because the array was centered about another rig in the dome, it was not in a fixed azimuthal plane relative to the engine. This has an as yet undetermined effect on the directivity, especially the tonal.

The tonal directivity as measured by the overhead array is shown in Figure 14 for the BPF tone (compare to Fig. 9). This data confirms the attenuation in the primary lobe when the fan tip speed is below sonic, and this attenuation occurs throughout the extended directivity. The lack of attenuation at supersonic fan tip speed is confirmed. Figure 15 compares the integrated overall PWL as computed from the overhead array. The $\sim 4$ to $5 \mathrm{~dB}$ broadband attenuation at the low fan speed in the forward sector is comparable to the 10-ft array results. The aft sector measurements show $\sim 2 \mathrm{~dB}$ broadband attenuation at the lower fan speed.

Figure 16 compares the $1 \mathrm{st}$ BPF tonal PWL integrated over the overhead array $\left(20^{\circ}<\Theta<140^{\circ}\right)$, and the 10 - $\mathrm{ft}$ array $\left(0^{\circ}<\Theta<90^{\circ}\right)$ versus rpm. The absolute values for the arrays are similar, indicating that the engine is significantly inlet-dominated at BPF. The attenuation comparison also supports the conclusion that the primary attenuation occurs in the inlet arc. Figure 17 compares the integrated overall PWL. As expected the overhead array is exposed to the aft noise, which is significant, and thus measures a higher PWL. The attenuation is greater from the inlet arc indicating that the overall PWL reduction is achieved primarily in the inlet. The trend comparison between the arcs is qualitatively complimentary and in general agreement.

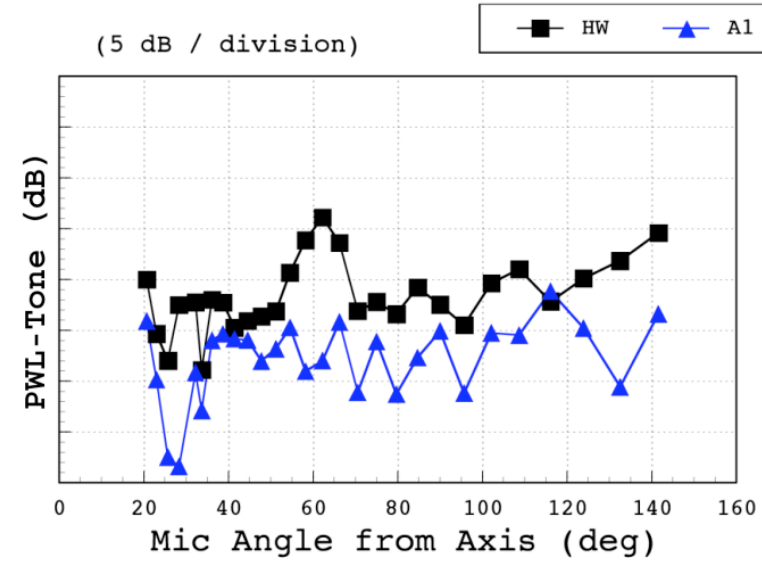

(a) Fan Tip Speed Below Sonic (N1c $=70 \%)$. (identical scales on plots)

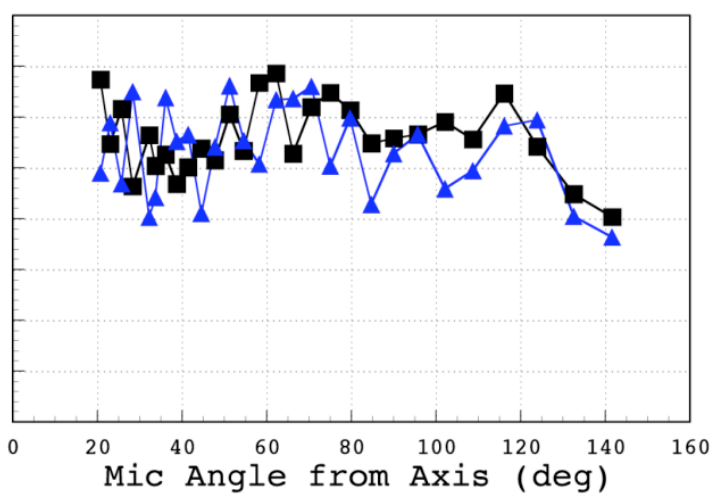

(b) Fan Tip Speed Above Sonic (N1c $=94 \%)$.

Figure 14.--Overhead Array 1st BPF Tonal Directivity for Two Fan Speeds.

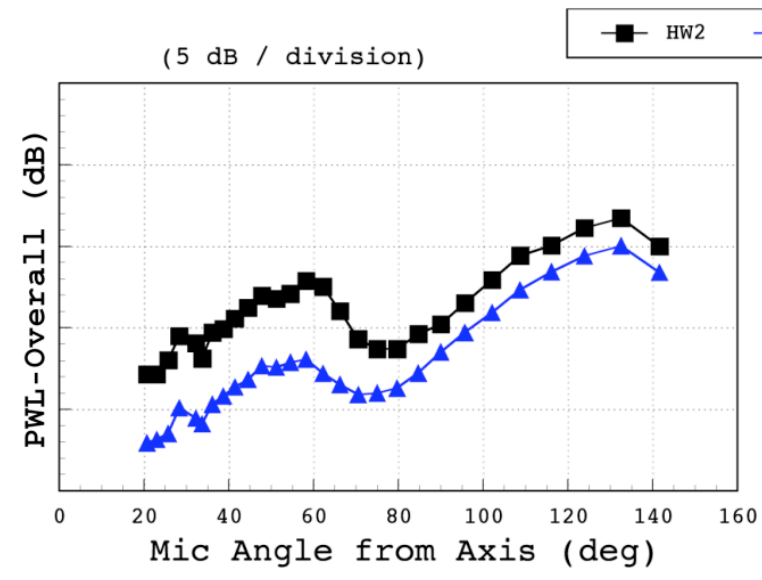

(a) Fan Tip Speed Below Sonic (N1c $=70 \%)$.

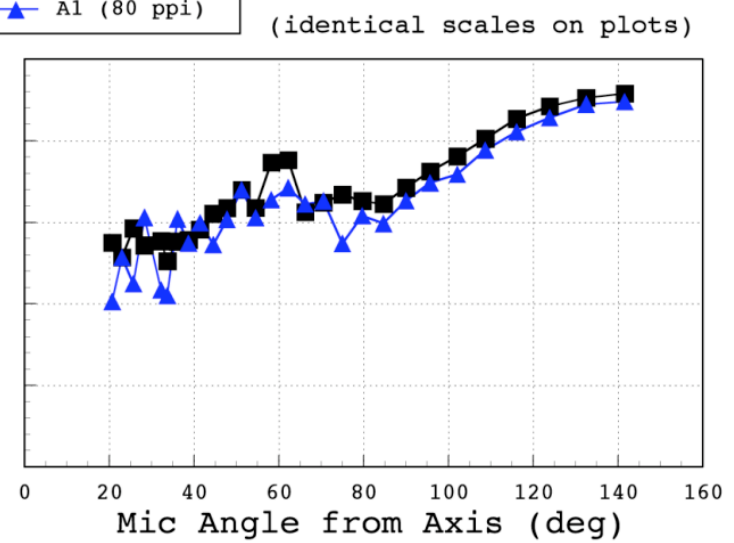

(b) Fan Tip Speed Above Sonic (N1c = 94\%).

Figure 15.-Overhead Array OAPWL Directivity for Two Fan Speeds. 

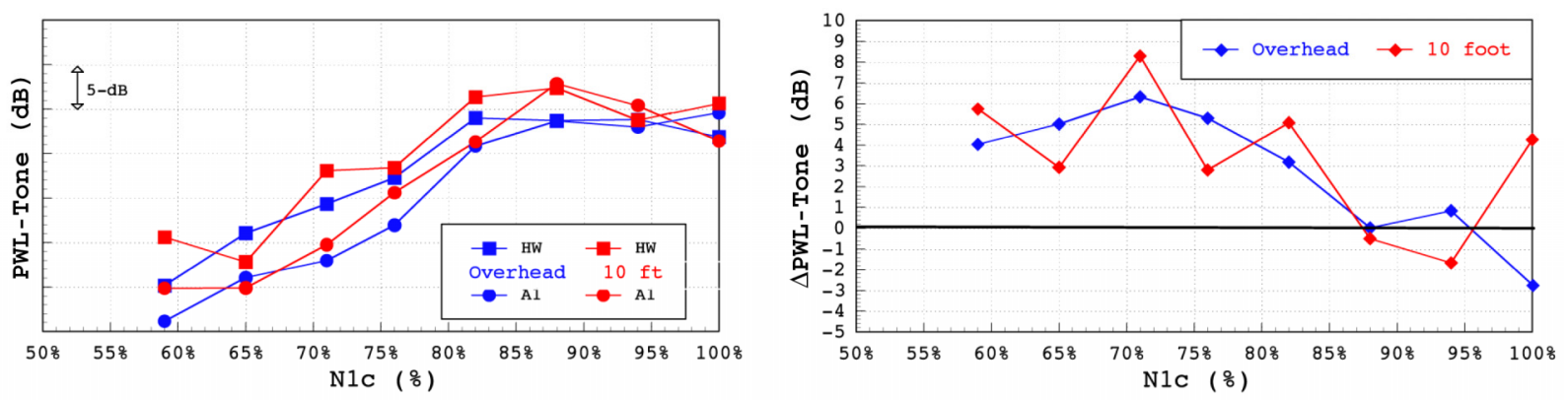

Figure 16.-BPF Tonal PWL Comparison Between 10-ft and Overhead Array.
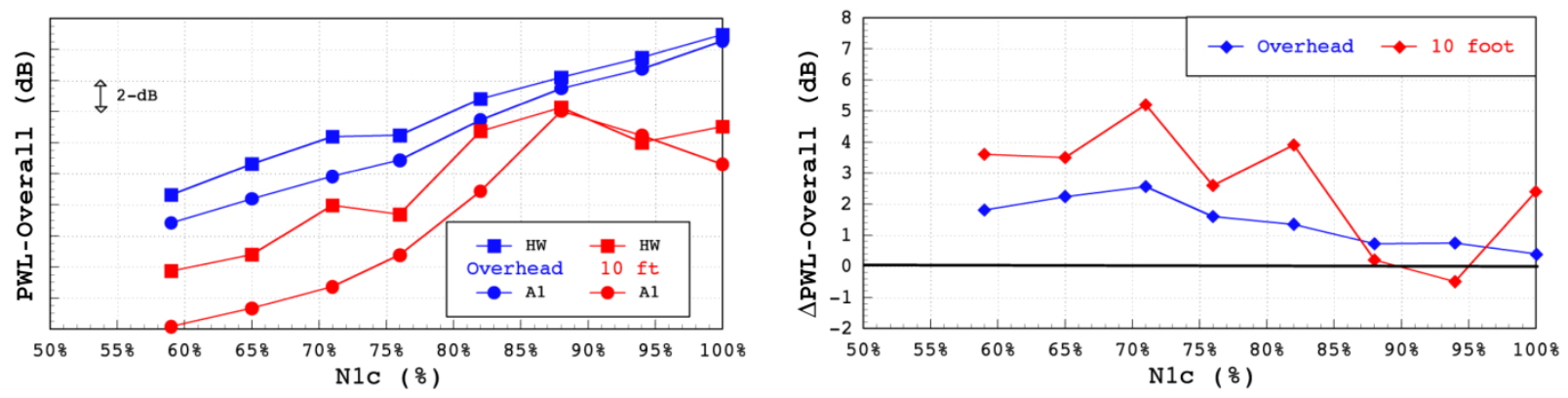

Figure 17.-Overall PWL Comparison Between 10-ft and Overhead Array.

\section{Effects on Engine Performance}

In order to evaluate the effects of the FML on the engine performance steady-state measurements were taken from rakes installed in the inlet duct and the fan bypass duct. Four total-pressure rakes ( 5 radial locations each) were installed in the inlet; 3 total-pressure, and 3 total-temperature rakes (also 5 radial locations each) were installed in the fan bypass duct. The static pressure was obtained from a port at the base of each rake. The rakes were equally spaced around the circumference. A photograph of representative rakes installed in an inlet are shown in Figure 18. Table I provides the radial locations of the rake ports.

Basic mass flow and adiabatic efficiency equations were used to calculate the performance. Since a determination of the "deltas" between configurations was the primary objective, the simple formulas shown in Equations (8) and (9) were sufficient. (These results matched the trends obtained from using the data in the Williams International engine deck performance simulation — not presented due to proprietary concerns.)

$$
\dot{m}=\pi \sqrt{\frac{2}{R}}\left(r_{o}^{2}-r_{i}^{2}\right) \sqrt{\left(\frac{P_{S}}{T_{t}}\right)\left(\frac{P_{t}}{P_{S}}\right)^{(\gamma-1) / \gamma}\left(P_{t}-P_{S}\right)}
$$

where $P_{s}$ is from the static pressure measured on the rake base, $P_{t}$ is from the inlet rakes, $T_{t}$ is the inlet temperature.

$$
\eta_{\text {adiabatic }}=P_{\text {tratio }}{ }^{\gamma /(\gamma-1)} /\left(T_{\text {tratio }}-1\right)
$$

where, $P_{t}$ ratio is the average of the exhaust total pressure rakes to the inlet total pressure rakes, $T_{t \text { ratio }}$ is the ratio of the average of the exhaust total temperature rakes to the inlet total temperature. (Note: Inlet total temperature is assumed to be the ambient temperature in both equations, which necessitated assuming a uniform inlet temperature.) 


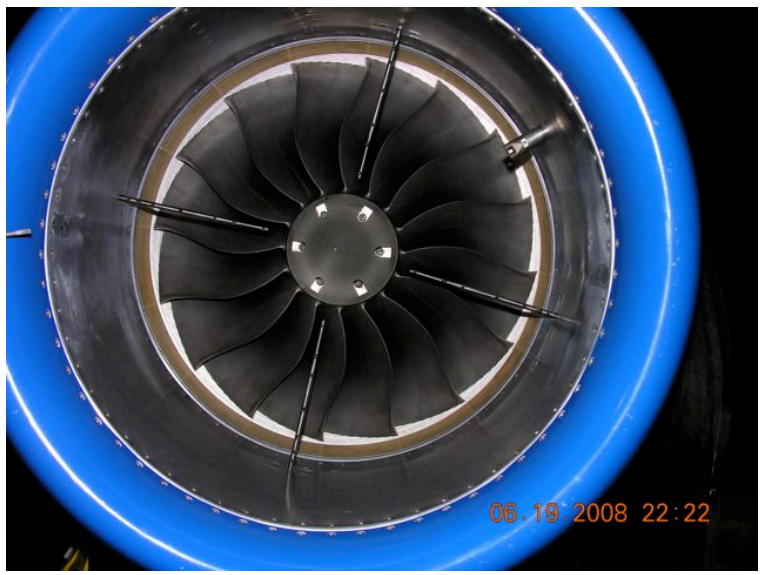

TABLE I.-RADIAL LOCATIONS OF PORTS

\begin{tabular}{|l|c|c|}
\hline \multicolumn{1}{|c|}{$P_{t} / T_{t}$-rakes } & Inlet & Bypass \\
\hline Outer Wall & 1.000 & 1.000 \\
\hline Port 5 & 0.946 & 0.907 \\
\hline Port 4 & 0.838 & 0.868 \\
\hline Port 3 & 0.710 & 0.833 \\
\hline Port 2 & 0.552 & 0.788 \\
\hline Port 1 & 0.326 & 0.749 \\
\hline Inner wall & 0.085 & 0.741 \\
\hline
\end{tabular}

Figure 18.-Photo of Inlet Steady-State Pressure Instrumentation.

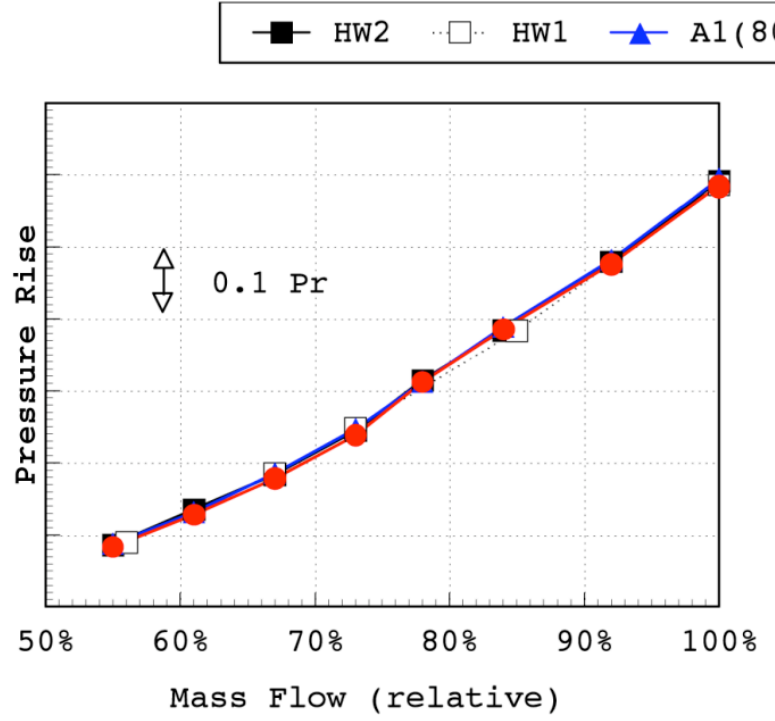

(a) Fan Pressure Rise

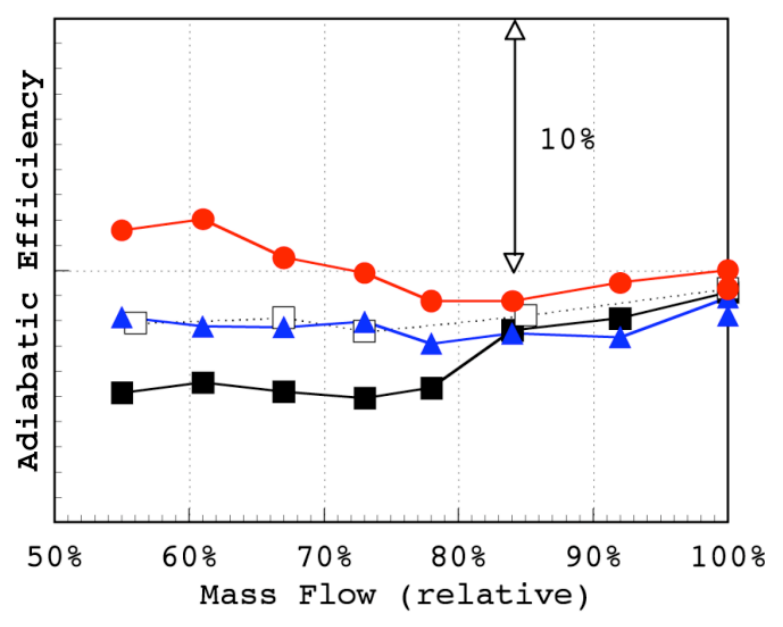

(b) Adiabatic Efficiency

Figure 19.-Schematic and Photo of Steady State Pressure Instrumentation.

The fan pressure rise and adiabatic efficiency are presented in Figures 19(a) and (b) as a function of mass flow (defining $100 \%$ mass flow at $100 \% \mathrm{~N} 1 \mathrm{c}$ ). The fan pressure rise is essentially unchanged as a result of the treatment. The adiabatic efficiency does appear to have a slight increase at the lower speed with treatment. At the off-design, lower fan speeds, the increase in efficiency is more apparent.

Tables II to IV are the results generated from the Williams International Engine simulation program based on the measured pressure and temperature data. Changes in thrust (Table II), stall margin (Table III), and specific fuel consumption (Table IV) are shown at 3 fan speeds. These changes are relative to the HW2 configuration (the circumferential grooves adjusted to match the modifications required for the FML) to best illustrate the effect of FML. These parameters show significant losses as a result of this modification. However the effect of the FML is subtle. In general, the higher ppi liner (A1-80 ppi) shows a loss in performance, whereas the lower porosity liner (A2-40 ppi) shows a slight increase in performance. The changes in performance are possibly due to changes in blade loading at the tip. 
TABLE II.-THRUST CHANGES

\begin{tabular}{|l|c|c|c|}
\hline$\Delta$ Fn & $100 \% \mathrm{~N} 1 \mathrm{c}$ & $88 \% \mathrm{~N} 1 \mathrm{c}$ & $70 \% \mathrm{~N} 1 \mathrm{c}$ \\
\hline $\mathrm{HW} 1$ & $3.0 \%$ & $3.5 \%$ & $5.6 \%$ \\
\hline $\mathrm{HW} 2$ & --------- & --------- & --------- \\
\hline $\mathrm{A} 2$ & $0.6 \%$ & $0.5 \%$ & $0.7 \%$ \\
\hline $\mathrm{A} 1$ & $-1.5 \%$ & $-2.2 \%$ & $-2.5 \%$ \\
\hline
\end{tabular}

TABLE III.-STALL MARGIN CHANGES

\begin{tabular}{|l|c|c|c|}
\hline S.M. & $100 \%$ N1c & $88 \%$ N1c & $70 \%$ N1c \\
\hline HW1 & $2.5 \%$ & $3.9 \%$ & $4.3 \%$ \\
\hline HW2 & -------- & -------- & --------- \\
\hline A2 & $0.4 \%$ & $0.5 \%$ & $0.5 \%$ \\
\hline A1 & $-0.9 \%$ & $-1.3 \%$ & $-1.7 \%$ \\
\hline
\end{tabular}

TABLE IV.-SPECIFIC FUEL CONSUMPTION CHANGES

\begin{tabular}{|l|c|c|c|}
\hline S.M. & $100 \% \mathrm{~N} 1 \mathrm{c}$ & $88 \% \mathrm{~N} 1 \mathrm{c}$ & $70 \% \mathrm{~N} 1 \mathrm{c}$ \\
\hline HW1 & $-0.4 \%$ & $-1.5 \%$ & $-4.6 \%$ \\
\hline HW2 & -------- & -------- & ------ \\
\hline A2 & $0.0 \%$ & $-0.1 \%$ & $-0.1 \%$ \\
\hline A1 & $0.2 \%$ & $0.6 \%$ & $1.2 \%$ \\
\hline
\end{tabular}

\section{Conclusion}

A FML was designed for and tested on an FJ44-3A turbofan engine. Farfield data from two arrays were acquired along with engine performance data. Over-the-Rotor FML installed at or near the fan rotor provide acoustic absorption of rotor noise. It also presents a pressure release boundary condition, inhibiting the rotor noise generation source.

Significant acoustic attenuation of the fan noise was observed. The liners were most effective below the sonic fan tip speed. Up to $5 \mathrm{~dB}$ of inlet PWL attenuation was achieved with overall PWL reduction was $21 / 2 \mathrm{~dB}$. The liners were seen to influence the engine performance, with the design condition $80 \mathrm{ppi}$ liner reducing performance 1 to $2 \%$; the off-design 40 ppi liner increasing the engine performance by $\sim 0.5 \%$.

Further investigation into the mechanism of the attenuation and performance changes will enable design of an optimum FML that could achieve significant noise reduction with minimal or no performance loss.

\section{References}

1. Huff, D.L., "Noise Reduction Technologies for Turbofan Engines," Proceedings of Inter-Noise 2006, IN06 732, December 2006.

2. Sutliff, D.L. and Jones, M.G., "Foam-Metal Liner Attenuation of Low-Speed Fan Noise," AIAA-2008-2897, also NASA/TM-2006-214368.

3. Lauer, J.T., McAllister, J., Loew, R.A., Sutliff, D.L., and Hartley, T.C., "FJ44 Turbofan Engine Test in the NASA Glenn Research Center's Aero-Acoustic Propulsion Laboratory," AIAA-2009-0620.

4. Aeroacoustics of Flight Vehicles: Theory and Practice—Volume 2: Noise Control, NASA RP-1258, Edited by H.H. Hubbard, August, 1991.

5. Jones, M.G., Parrott, T.L., Sutliff, D.L., and Hughes, C.E., "Design and Evaluation of Soft Vane and Metal Foam Noise Reduction Concepts," AIAA-2009-3142.

6. Chung, J.Y. and Blaser, D.A., "Transfer Function Method of Measuring In-duct Acoustic Properties: I. Theory," Journal of Acoustical Society of America, vol. 68, 1980, pp. 907-921.

7. Jones, M.G. and Parrott, T.L., "Evaluation of a Multipoint Method for Determining Acoustic Impedance," Journal of Mechanical Systems and Signal Processing, vol. 3, no. 1, 1989, pp. 15-35.

8. Smith, C.D. and Parrott, T.L., "Comparison of Three Methods for Measuring Acoustic Properties of Bulk Materials," Journal of Acoustical Society of America, vol. 74, no. 5, 1983, pp. 1577-1582.

9. Cooper, B.A., "A Large Hemi-Anechoic Chamber Enclosure for Community-Compatible Aeroacoustic Testing of Aircraft Propulsion Systems," Journal of the Institute of Noise Control Engineering of the USA, Jan/Feb 1994. 


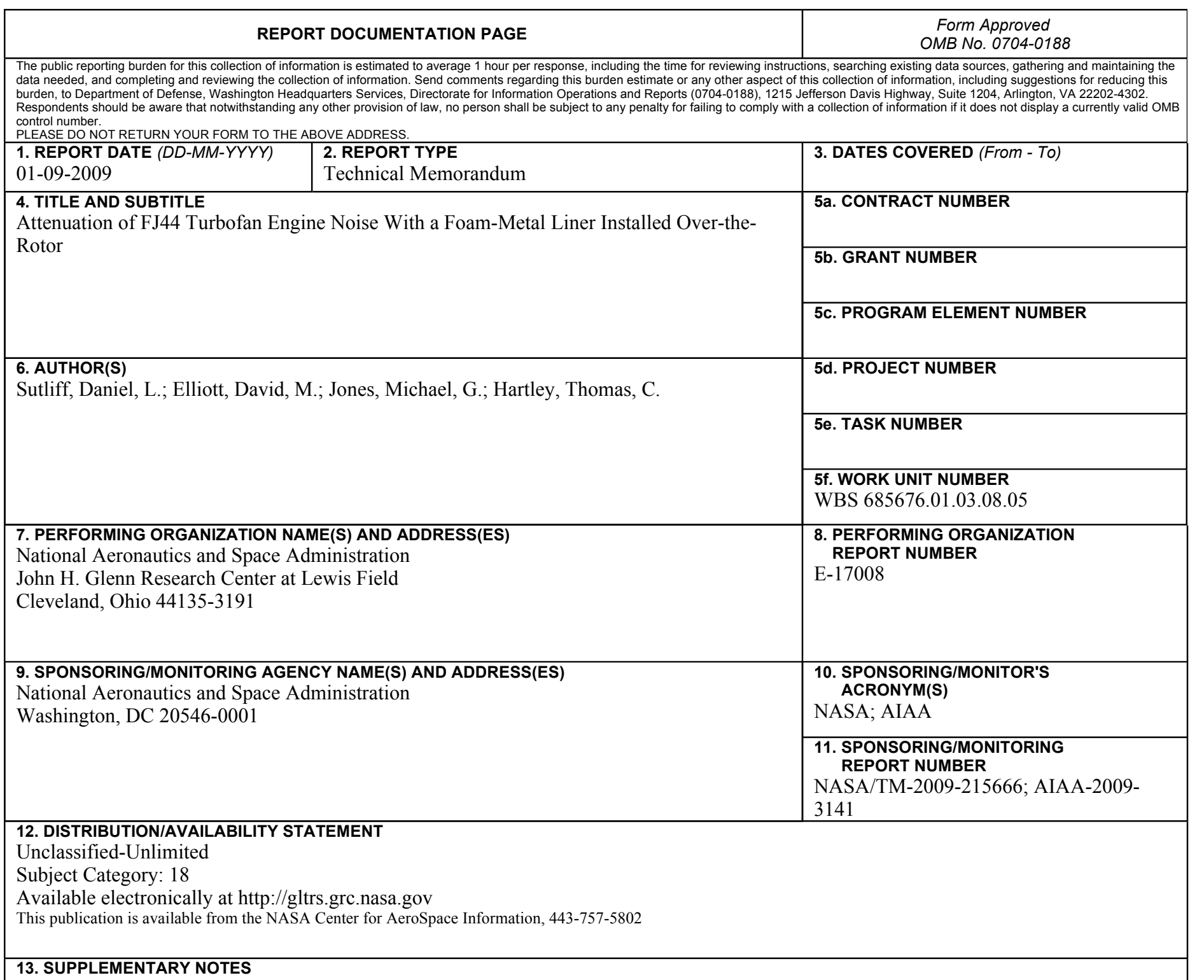

\section{SUPPLEMENTARY NOTES}

\section{ABSTRACT}

A Williams International FJ44-3A 3000-lb thrust class turbofan engine was used as a demonstrator for a Foam-Metal Liner (FML) installed in close proximity to the fan. Two FML designs were tested and compared to the hardwall baseline. Traditional single degree-of-freedom liner designs were also evaluated to provide a comparison. Farfield acoustic levels and limited engine performance results are presented in this paper. The results show that the FML achieved up to $5 \mathrm{~dB}$ Acoustic Power Level (PWL) overall attenuation in the forward quadrant, equivalent to the traditional liner design. An earlier report presented the test set-up and conditions.

\section{SUBJECT TERMS}

Fan noise; Liners

\begin{tabular}{|c|c|c|c|c|c|}
\hline \multicolumn{3}{|c|}{ 16. SECURITY CLASSIFICATION OF: } & \multirow{2}{*}{$\begin{array}{l}\text { 17. LIMITATION OF } \\
\text { ABSTRACT } \\
\text { UU }\end{array}$} & \multirow{2}{*}{$\begin{array}{l}\text { 18. NUMBER } \\
\text { OF } \\
\text { PAGES } \\
19\end{array}$} & \multirow{2}{*}{$\begin{array}{l}\text { 19a. NAME OF RESPONSIBLE PERSON } \\
\text { STI Help Desk (email:help@sti.nasa.gov) } \\
\text { 19b. TELEPHONE NUMBER (include area code) } \\
\text { 443-757-5802 }\end{array}$} \\
\hline $\begin{array}{l}\text { a. REPORT } \\
U\end{array}$ & $\begin{array}{l}\text { b. ABSTRACT } \\
U\end{array}$ & $\begin{array}{l}\text { c. THIS } \\
\text { PAGE } \\
\text { U }\end{array}$ & & & \\
\hline
\end{tabular}



